\title{
Testing properties governing the durability of lime-based repair mortars
}

\author{
Ioanna Papayianni ${ }^{1 *}$, John Hughes ${ }^{2}$ \\ 1 Laboratory of Building Materials, School of Civil Engineering, Aristotle University of Thessaloniki, Greece \\ 2 School of Computing Engineering and Physical Science, University of West Scotland, Paisley Campus, United Kingdom
}

Received: 14 February 2019 / Accepted: 07 March 2019 / Published online: 18 March 2019

(C) The Author(s) 2019. This article is published with open access and licensed under a Creative Commons Attribution 4.0 International License.

\begin{abstract}
Lime-based mortars - are preferred for the repair of historic structures, where they were used in the construction of the original. The long-term performance of repair lime mortars is closely related to durability issues, concerning the old structure's substrate, the new repair mortars and the interface between the two, which is also much influenced by the technique of mortar's application.

Durability is a multifunctional property affected by a number of parameters, including local environmental conditions. However, experience shows that some characteristics of materials play a dominant role for assessing the durability of repair lime mortars and have a direct impact on the longevity of the repaired structure.

This paper presents a review of research; case studies and Master/PhD projects supervised by members of the RILEM TC 277-LHS. Through this review we evaluate research and common practice concerning durability challenges and attempt to answer questions arising when assessing the durability of repair lime mortars including: 1) The most often encountered failures, due to inadequate mortar durability, 2) The characteristics of mortars that influence durability, 3) The methods used for testing the durability of lime-based mortars, with an evaluation of their applicability and performance, 4) The importance of quality control and on-site execution practices.
\end{abstract}

Keywords: Lime-based; Mortar; Durability; Test methods; Quality control; Execution practices

\section{Introduction}

Lime-based repair mortars are generally preferred for the repair of historic structures, since they are considered more compatible with the authentic historic fabric, from the point of view of the physico-chemical, mechanical and elastic characteristics. These are also closely related to moisture transport phenomena and deformability under the action of mechanical and hydrothermal loads. In general, they consist of a mixed-type binding system, such as lime + a hydraulic binder component. Lime mortars develop low to moderate strength and possess high porosity after hardening, in comparison to cement-based mortars. However, any repair intervention aims for a long life expectancy and the protection of historic structures and also a great social and economic impact. Therefore, durability aspects related to environmental exposure should be taken into account in designing a lime-based repair mortar.

According to $\mathrm{ACl}$ Committee 201 [1], the durability of concrete is defined as the ability to resist the action of weathering and other deterioration processes, and at the same time retain serviceability when exposed to the intended service environment. In the case of repairing historic structures with lime-based mortars, the long-term performance of mortars is more complex compared with concrete. Restoration mortars' durability depends on [2]:

- The environmental exposure conditions (inducing salt contamination from air pollution, acid rain, frost, thermal dilation, wetting-drying, wind weathering, biological attack).

- The characteristics of the substrate to which a mortar is applied to (compatibility with substrate).

- The ingredients used to make the mortar, i.e. its composition (binder, aggregate, additives, admixtures and water), that influence porosity, mechanical and elasticity characteristics, as well as deformability.

Maintenance (lack of which leads to premature failures, worsening damage).

- On site construction practices.

Furthermore, historic structures often include different composite masonry elements, consisting of masonry units and mortars, such as single-leaf or two-leaf stone masonry walls. Lime-based mortars may serve as bedding, re-pointing, rendering / plastering mortars or even complete the missing parts of ancient floors or architectural surfaces [3]. The

* Corresponding author: I. Papayianni, E-mail: papayian@civil.auth.gr 
requirements for their good performance differ analogously to their functional role in their host building. For example, for bedding, mechanical and elastic characteristics are of major importance, while in renders and plasters the adhesion to substrate and consequent interactions (salt migration from substrate to mortar) are of paramount significance. When using lime-based mortars for repair, a weak bond with substrate is often formed, although hydrated lime is a sticky constituent of high water retention and favors adhesion.

\section{Durability of repair mortars}

The most common types of problem damage that repair works carried out with lime-based mortars are intended to remedy can include:

- cracking,

- rising damp,

- salt accumulation resulting in scaling, delamination, granular disintegration,

- loss of mortar cohesion, or bond with substrate,

- freeze thaw damage,

- wind weathering,

- colour alteration.

In some real repair projects [4, 5], a systematic diagnostic investigation is made before designing the recipe for a repair mortar. However, what mixture was actually applied, and details of the execution of the work, as well as long-term monitoring data are not often available. Therefore, the validation of the parameters that play an essential role in degradation processes is not usually possible. In many cases, the damage symptoms are aggravated or can be transferred to previously unaffected areas.

Experimental research on durability aspects in repairing historic structures dates from the beginning of the $20^{\text {th }}$ Century. Studies mostly address stone damage and limecement or masonry cement mortars, which possess finer capillaries than bricks [6]. Important topics covered in previous research include water movement inside the system of continuous pores in the form of liquid by capillarity and infiltration under hydrostatic pressure, and vapor by condensation and hygroscopicity, depending on the nature of mortar constituents and the presence of salt [7].

A significant and perennial topic for mortar durability involves the mortars' composition, the action of salt, and the importance of temperature and $\mathrm{RH}$ in crystallization habits as well as which salt is more destructive. It has proven difficult in salt deterioration research to separate specific mechanisms of damage creation, but variations in temperature and relative humidity do appear to be the main controls on deterioration [8].

More recently (post 2000) research on damage induced by salts is intensively studied using accelerated test methods [9]. Efforts were also made to simulate better the environmental conditions and to avoid destructive effects due to drying (cracking) [10]. Research becomes increasingly oriented towards studying lime-based mortars in more complex ways, paying attention to pore system characteristics, their evolution with time and the effects of environment [11]. Studies also increasingly focus on specialised functions of mortars (repointing, renders/plasters etc.) and investigate properties and mechanisms of damage by using advanced methods (e.g. NMR for detecting the drying behavior [12]).

Two EU Projects ASSET (2000) and COMPASS (2001) gave a great impetus to research and precious knowledge acquisition $[5,13]$. Smart mathematical models are proposed for calculating excess crystallization pressure [14] and indices such as $(\mathrm{Pe})$ [12], relating capillarity moisture with diffusion coefficient and drying rate. The concept that the drying behavior of a plaster substrate layer depends on the pore size distribution of both (plaster +substrate) is supported by researchers working separately.

Apart from salt crystallization, pressure damages seem to be associated with other mechanisms such as hydration pressure. Differential thermal expansion and hygric dilation by deliquesce crystallization cycles cause irreversible hygric expansion leading to powdering [5]. In the literature review [15] all parameters involved in moisture and salt transport have been critically peer viewed. It could be said that the last 20 years, better understanding of mechanisms of salts behavior in pore systems of materials has been achieved.

\section{Properties of repair mortars influencing durability}

Based on the reports of RILEM TC 203-RHM [16], and discussion in the current (at the time of publication) running TC 277-LHS, for all lime-based mortars the properties related to durability for good, long-term performance are:

- Porosity and pore size distribution, associated with capillary water absorption, drying, water vapor permeability, hygroscopicity, frost resistance and salt crystallization.

- Mechanical strength: compressive and tensile strength

- Elasticity: Modulus of elasticity, deformability (capacity of the material to accommodate elastic/plastic deformations).

- Shrinkage (early and long term).

- Adhesion, shear, flexural and tensile bond.

- Thermal dilation coefficient.

Specific characteristics such as colour and colour stability (for architectural surfaces and renders) and abrasion resistance for flooring mortars, are also considered for the durability of repair mortars. Specific functional classifications of mortar, and the requirement frameworks they are designed to meet, imply that significant properties relevant to durability will be different for different mortars.

As is well known, the hardened porosity of a mixture of inorganic constituents and water, is mainly determined by the water/binder (W/B) ratio, since the ultimate water content and porosity relationship is linear for a great range of materials [17] and it is the most influential parameter for the strength development in the hardened state. Differences in $\mathrm{W} / \mathrm{B}$ lead to differences in porosity (pores involved in capillary transport). In the case of lime with a hydraulic component 
binding systems, in which the strong hydraulic component (cement) content is $<30 \%$ by mass, the porosity and strength evolution is slow; it could be said that it is stabilized after 90 days. The predominant pore sizes range between 100-600 $\mu \mathrm{m}$. Other parameters influencing both porosity and strength are the type of binder, the content, grain size and granulometric curve of aggregates as well as the curing conditions during hardening [18]. In lime-cement mortars the higher the content in cement, the finer the pores in the matrix. A compact and even granulometric curve leads to mortars with less porosity. Aggregates also influence the modulus of elasticity [17]. The higher the content and grain size of aggregates in mortars, the greater is the modulus of elasticity.

Moisture is always present in mortars, since water is added in excess in mortar mixtures for achieving adequate workability. This may be chemically or physically bound, or exist due to absorption following hardening by capillary action. As saturation of capillary pores decreases with time (the rate depends on ambient temperature and relative humidity), an increase in capillary suction is developed and microcracks may occur if saturation is not homogeneous. Drying process takes place and shrinkage deformations lead to micro-cracks (mostly at the interfaces between mortar/substrate, matrix/aggregate) if they are restricted and tensile strength is not adequate.

Adhesion and bond strength is influenced by the binder matrix and mortar composition as well as the properties of the substrate masonry unit (absorption, porosity, surface characteristics) [19]. Workmanship (pressure exerted during mortar's bedding) is also important for the uniform extent of adhesion and bond. Lime content in mortars favors the plasticity, adhesion and self-healing of macro-cracks. Moisture flow between mortar substrate is essential for good adhesion.

According to reference [20] the bond strength rather than mortar's strength determines the strength of masonry. The rate of brick absorption and mortar's water retention are essential for bond development.

\section{Test methods for assessing the durability of lime-based mortars}

The most common test methods for assessing durability are: wetting-drying cycles, freeze-thaw cycling and salt crystallization damage tests. They are of accelerated type aiming at pre-estimation of mortar's resistance to its intended environment of exposure. Existing standard methods, RILEM recommendations or proposed test procedures in the literature [21-23] do not provide reliable results particularly in the case of "soft" lime based mortars with a relatively coarse porosity. In the report of RILEM TC 271-ASC [24] the difficulties in interpreting and comparing results taken from salt crystallization tests are highlighted. The key influential parameters are discussed towards the development of a more realistic and accurate method of testing. The trend in regulations for masonry control is to use composite (masonry unit and mortar) or wallettes for testing resistance to frost
[25]. Another example is the procedure for testing resistance of renders/plasters to salt damage proposed in [22]. In the case of composite specimen testing the residual adhesion after weathering can also be checked. In general it is recommended that salt tests should be tailored to achieve specific objectives related to the real world deterioration mechanism [15]. This approach can develop bespoke experimental approaches, which are ideal for scientific analysis. However, it may not be easily applied in every day restoration projects, as such a test procedure is usually designed by a specialist.

On the other hand it seems that in cases where the effect of mortar constituents on weathering is under question (i.e. type of binder, grain size and granulometric curve of aggregates) [26-27] testing the mortar itself is more convenient. Similar case is the comparison of the influence of admixtures (i.e. superplasticizers, water retainers, linseed oil, PCM additives) or other minor constituents (fibres, selfhealing) on resistance to weathering [28-19].

Standard test methods for testing durability are de facto validated in practice, if the resistance of a material is predicted by the application of the test That is why standard test methods are revised based on feedback from real case studies. Revision of standards is the responsibility of CEN. However, RILEM TCs often deal with revision objectives and suggest amendments in existing standards at pre normative level, according to experience from practice such as RILEM TC 277-LHS concerning the testing of lime-based mortars.

\section{On-site execution practices}

Something that has been widely recognized by experts [4, 30] involved in laboratory and on site works, as missing from the construction guidance literature, is a manual of practice concerning the onsite execution of good practices for each type of lime-based mortars (bedding, repointing, renders/ plasters, flooring and architectural surface repair). As pointed out by Maurenbrecher et al. [2] "successful performance of mortar repair works depends $50 \%$ on appropriate design and $50 \%$ on how well the work is executed on site". Inspection at each stage of construction or repair work is essential as well as proper curing. A maintenance guide including data of the survey made and a schedule of regular visual inspection (including a checklist) are of great importance.

Since restoration works are of high cost projects and any failure after repair has a destructive effect on authenticity and integrity of historic structures, it is advisable the whole execution procedure be checked by applying a quality control system. That means accompanying measures always should be taken such as:

- Development of sound reliable testing methods for limebased mortars.

- Development of field tests to help restorers to make decisions.

- Development of guide or manual of practice with instructions for different types of field works.

- Establishing a system of controlling the quality of repair material and execution works (i.e. taking samples from 
mortars applied for testing, inspecting the work done, noting any curing precautions taken, etc).

There are many approaches to this in many parts of the world already in existence, depending on local regulation and conservation practice. Furthermore, the supervisors should deliver accurate record documents concerning environmental conditions, materials and works done. Other accompanying measures could be the organization of training and certification programmes for technicians and inspectors.

\section{Conclusions}

The long-term serviceability of lime-based mortars depends on designing mixtures with predicted resistance to the intended service environment. Previous research reveals mechanisms of decay from weathering and other processes, especially salt decay. Efforts are made to incorporate advanced knowledge in test methods for more accurate and applied, realistic results.

The governing durability properties are often adversely interrelated. Designing lime-based repair mortars for meeting durability requirements, the substrate properties should be taken into account particularly in render, plaster and repointing mortars. Modification to existing standard test methods could lead to more reliable results.

Apart from test methods, the quality control of execution practices and development of relevant manual of practice is of equal importance. Advice already exists, at various national levels, to assist with site practice, but its relationship to standardised materials specification and the role it plays in improving durability outcomes is not to date clear.

In the frame of RILEM TC 277-LHS a strategic plan of activities has been scheduled with the aim of harmonising test methods for lime-based repair materials, such as:

- Review of the current standard test methods of mortars or to develop proposals for adjustment for the more realistic and effective evaluation of lime-based mortar.

- Adaptation and development of simple field test methods to assess the behaviour and performance of lime-based mortars on site, facilitating the quality control of repair works.

- Evaluate the proposed adaptations to test methods for lime-based mortars by organising experimental work and/or round robin test programmes.

- Motivate stakeholders in the public and private sectors to share their experiences from practice and to open an interactive dialogue with them about the performance and the feasibility of the proposed modifications to test methods and on-site practice.

\section{Acknowledgements}

This paper was prepared by loanna Papayianni (TC chair) and John Hughes (TC member) within the framework of the activities of RILEM TC 277-LHS. The contribution of the members of TC 277-LHS is gratefully acknowledged

\section{References}

[1] ACl Committee 201, Guide to Durable Concrete, ACl Manual of Concrete Practice, 2002.

[2] P. Maurenbrecher, C. Groot,, Repair Mortars for Historic Masonry, State of the Art Report of RILEM TC 203 RHM, RILEM Report, Paris (France), 2016.

[3] J.J. Hughes et al., The Role of Mortar in Masonry: an Introduction to Requirements for the Design of Repair Mortars, Mater Struct (2012) 45:1287-1294. https://doi.org/10.1617/s11527-012-9847-9

[4] M.R. Veiga, Conservation of Historic Renders and Plasters from Lab to Site, 2nd International Conference on Historic Mortars, Proceedings of HMC2010, Prague, September, 2010 (RILEM TC 203 RHM) 12411256.

[5] B.A. Lubelli, Sodium Chloride Damage to Porous Building Materials, PhD thesis, Appendix 2, (2006) 25-42.

[6] R. Van Hees, B.A. Lubelli, L. Pel, H. Huinnink, C. Groot, M. Rooij, Transport and crystallization of salts in masonry and plasters, 13th International Brick/Block Masonry Conference, Proceedings of IB2MaC, Amsterdam, 2004, 711-727.

[7] C.A. Price, Salt damage of monuments and means of control, Bournemouth University School of Conservation Sciences, Bournemouth, 1996.

[8] A.E. Charola, Salts in deterioration of porous materials, J Am Inst Archit 39 (2000): 327-34

[9] P. Faria-Rodrigues (2009), Resistance to salts of lime and pozzolan mortars. In: RILEM Proc. PRO 067, Repair mortars for Historic Masonry, 99-110

[10] B. Lubelli, R.P.J. van Hees, C.J.W.P. Groot, The effect of environmental conditions on sodium chloride damage, Stud Cons 51 (1) (2006):4156. https://doi.org/10.1179/sic.2006.51.1.41

[11] Papayianni, M. Stefanidou, Strength-porosity relationships in limepozzolan mortars, Constr Build Mater (2006) 20:700-705. https://doi.org/10.1016/j.conbuildmat.2005.02.012

[12] Pel, H. Huinink, K. Kopinga, Salt transport and crystallization in porous building materials, Magn Reson Imaging (2003) 21:317-320. https://doi.org/10.1016/S0730-725X(03)00161-9

[13] T.D. Gonzales, Salt crystallization in plastered or rendered walls, $\mathrm{PhD}$ thesis, University of Lisbon, Lisbon, (2007).

[14] R. Flatt, et al., Predicting salt damage in practice. A theoretical insight into laboratory tests, RILEM Tech Lett (2017) 2: 108-118. https://doi.org/10.21809/rilemtechlett.2017.41

[15] A.E. Charola, I. Roring-Dalgaard, J. Chwast, J. Elsen, Salt crystallization tests. Focus on their objective', in 'SWBSS 2017 - 4th International Conference on Salt Weathering of Buildings and Stone Sculptures, Proceedings of an International Conference, Potsdam, Germany, September, 2017.

[16] RILEM TC 203 RHM, Repair Mortars for Historic Masonry: Testing of hardened mortars, a process of questioning and interpreting, Materials and Structures (2009) 42: 853-865. https://doi.org/10.1617/s11527-008-9455-x

[17] K. Mehta, P. Monteiro, Concrete Microstructure, Properties and Materials, Mc Grow Hill, 3rd ed., (2006): 49-50.

[18] I. Papayianni, Design of compatible repair materials for the restoration of monuments, Int J Restor (2004) 10: 623-635.

[19] M. Lawrence, P. Walker, Z. Zhou, Influence of interfacial pore structure on the strength of the brick-lime mortar bond, -2nd International Conference on Historic Mortars, Proceedings of HMC2010, Prague, (2010), (RILEM TC203 RHISTORIC STRUCTURES) 519-527.

[20] A. Costigan, S. Pavia, Influence of mechanical properties of lime mortar on strength of masonry, 2nd International Conference on Historic Mortars, Proceedings of HMC2010, Prague, (2010), (RILEM TC203 RHISTORIC STRUCTURES) 457-467

[21] S. Botas, V.M. Rato, P. Faria, Testing the freeze-thaw cycles in lime mortars, 2nd International Conference on Historic Mortars, Proceedings of HMC2010, Prague, (2010), (RILEM TC203 RHISTORIC STRUCTURES) 417-427.

[22] T. Wiffels, B. Lubelli, Development of a new accelerated salt crystallization test, Heron (2006) 51: 63-79.

[23] A.L. Velosa, R.M. Veiga, Development of artificial ageing tests for renders. Application to conservation mortars, Proceedings of Int. Masonry Conference, London, November, 2006.

[24] A.B. Lubelli, Towards a more effective and reliable salt crystallization test for porous building materials: State of the art, Mater Struct (2018) 51: 55. https://doi.org/10.1617/s11527-018-1180-5 
[25] RILEM TC 127-MS, MS-A4, Determination of the durability of hardened mortars, Mater Struct (1998) 31: 11-15.

[26] K. von Thorborg, Design of non hydraulic and hydraulic lime mortars appropriate for restoration in Nordic climate, in '1st HMC', Proceedings of an International Conference, Lisbon, September, 2008.

[27] A. Arrizi, H. Viles, G. Cultrone, Experimental testing of the durability of lime based mortars for rendering historic buildings, Constr Build Mater (2012) 28: 807-813.

https://doi.org/10.1016/j.conbuildmat.2011.10.059

[28] B. Nunes, Z. Slizkova, D. Krivankova, Lime based mortars with linseed oil: Sodium chloride resistance assessment and characterization of the degraded material, Period Mineral (2013) 82: 411-427.

[29] L. Kyriakou, M. Theodoridou, I. Ioannou, Assessment of the durability of lime renders with Phase Change Material (PCM) additives against salt crystallization, in 'SWBSS 2017 - 4th International Conference on Salt Weathering of Buildings and Stone Sculptures', Proceedings of an International Conference, Potsdam, Germany, September, 2017, 8189.

[30] J. Cooke, M.I. Subercasceaux, W.Y. Mou, Practical case study: mortar conservation for the Connaught Building, Ottawa, Ontario, Canada, 2nd International Conference on Historic Mortars, Proceedings of HMC2010, Prague, 2010, (RILEM TC203 HISTORIC STRUCTURES) 573581. 